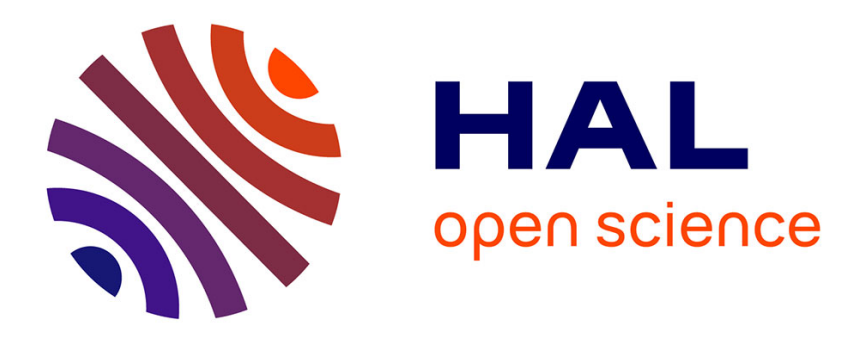

\title{
Phase separation dynamics of a polymer dispersed liquid crystal
}

T. Kyu, I. Ilies, M. Mustafa

\section{To cite this version:}

T. Kyu, I. Ilies, M. Mustafa. Phase separation dynamics of a polymer dispersed liquid crystal. Journal de Physique IV Proceedings, 1993, 03 (C8), pp.C8-37-C8-40. 10.1051/jp4:1993808 . jpa-00252227

\section{HAL Id: jpa-00252227 https://hal.science/jpa-00252227}

Submitted on 1 Jan 1993

HAL is a multi-disciplinary open access archive for the deposit and dissemination of scientific research documents, whether they are published or not. The documents may come from teaching and research institutions in France or abroad, or from public or private research centers.
L'archive ouverte pluridisciplinaire HAL, est destinée au dépôt et à la diffusion de documents scientifiques de niveau recherche, publiés ou non, émanant des établissements d'enseignement et de recherche français ou étrangers, des laboratoires publics ou privés. 


\title{
Phase separation dynamics of a polymer dispersed liquid crystal
}

\author{
T. KYU, I. ILIES and M. MUSTAFA \\ Institute of Polymer Engineering, The University of Akron, Akron, OH 44325, U.S.A.
}

\begin{abstract}
Phase separation in a polymer dispersed liquid crystal (PDLC), consisting of a main chain liquid crystal (E7) and polymethyl methacrylate (PMMA), was studied by means of light scattering and optical microscopy. The PMMA/E7 mixture exhibits an upper critical solution temperature (UCST), overlapping with a nematic-isotropic transition of the E7 liquid crystal. Several temperature quenches were undertaken by rapidly transferring the 60/40 PMMA/E7 from a single phase $\left(95^{\circ} \mathrm{C}\right)$ to an unstable region $\left(25,35\right.$ and $\left.45^{\circ} \mathrm{C}\right)$ and by subsequently monitoring the time-evolution of scattering profiles. The time-evolution of structure factor reveals a cross-over of a kinetic exponent from -0.33 to -0.6 or larger slopes at a shallower temperature quench. Multiple droplets appear under a polarized microscopic investigation. Concurrently, nematic disclinations develop within the droplets and annihilation occurs as droplets coalesce.
\end{abstract}

\section{Introduction}

Recent advances in the field of liquid crystal optical materials have received considerable attention in industries and academia. ${ }^{1-5}$ Among them, polymer dispersed liquid crystals (PDLC) and polymer stabilized cholesterics (PSC) are promising materials for display applications. PDLC films are operated based on the principle of modulating electric field. $^{2}$ In the off-state, the PDLC films are turbid due to the mismatch of refractive indices between the randomly oriented LC molecules and matrix polymer. Under an electric field, the LC directors are oriented in the direction of electric field within phase separated domains. Since the refractive index of polymer binder could be generally matched with that of the ordinary component of LC, the film appears transparent to naked eye.

PDLCs are generally prepared via phase separation of an initially homogeneous mixture of polymer and liquid crystal (LC) either by thermal quenching or by polymerizing functional prepolymers. ${ }^{1}$ As the switching characteristic of PDLC has been known to depend on the domain size, the shape and the dispersion, it is crucial to understand the mechanism of phase separation and dynamics of phase growth. In a previous paper, 5 we reported thermodynamic phase equilibria and structure evolution of a mixture of atactic PMMA and E7 liquid crystal following continuous cooling and thermal quenching. In this paper, we focus our attention on the dynamics of phase separation and nematic formation within the preformed droplets.

\section{Experimental}

A main chain liquid crystal, commercially known as E7 (EM Industries), is a mixture of cyanobiphenyl (CB) moieties, comprising 5CB (51 wt\%), 7CB (25\%), $8 \mathrm{OCB}(16 \%)$ and cyanotriphenyl $5 \mathrm{CT}(8 \%)$. The prefix number represents the numbers of carbon atoms in methylene linkages. Although the structure of E7 is seemingly complex, it displays a phase transition behavior reminiscent of that of a single-component liquid crystal. For instance, it exhibits a single nematic-isotropic transition at $61^{\circ} \mathrm{C}$ and a single crystal-nematic transition at $-10^{\circ} \mathrm{C} .1,2$ Thus, E7 based PDLC may be viewed as a pseudo two-phase system. Atactic PMMA used in this study has an average molecular weight $\mathrm{Mw}=55,000$ with a polydispersity $\mathrm{Mw} / \mathrm{Mn}=1.05$. PMMA was dissolved in tetrahydrofuran (THF) and $\mathrm{E} 7$ was added in desired amounts to make the blends. Thin films were solvent casted on glass slides by evaporating THF for cloud point determination and further compression molded at $100^{\circ} \mathrm{C}$ for kinetic experiments. 
Cloud point temperatures were determined by measuring the abrupt change of scattered light at a given scattering angle with a heating and cooling rate of $0.5^{\circ} \mathrm{C} / \mathrm{min}$. The light scattering set-up was equipped with a He-Ne laser $(2 \mathrm{~mW}$ ), a photomultiplier, a pre-amplifier, a goniometer (ART 306, Aerotech), a stepping motor (45SMB2, Areotech) and a motion controller (Unidex XI, Aerotech). A temperature controller (RTD 2012, Omega) and the motion controller were interfaced to a microcomputer (IBM PC/2) to synchronize the experiment. The scan speed was $5 \%$. The intensity readout and post data analysis were undertaken by the same microcomputer. Optical micrographs were taken on an optical microscope (Optiphot2-pol, Nikon) by using a $35 \mathrm{~mm}$ Nikon camera.

\section{Results and Discussion}

The PMMAV7 PDLC films were cloudy at room temperature because of structural inhomogeneity. Upon heating above the N-I transition temperature of E7, the film turns transparent as the mixture is homogenized into a single phase. However, the system reverts to a two-phase state upon cooling, indicating thermal reversibility of the system. Figure 1 exhibits a cloud point temperature versus composition phase diagram for the PMMA/E7 mixture. It is basically an upper critical solution temperature (UCST), overlapping with a N-I transition of the E7 liquid crystal. The convex maximum of the UCST is located at a slightly higher temperature $\left(63^{\circ} \mathrm{C}\right)$ than that of the N-I transition of neat E7 which is about $60^{\circ} \mathrm{C}$. Thus, the UCST may be attributed to liquid - liquid phase separation between polymer and isotropic phase of E7. The cloud point measurement of the 90\% E7 composition reveals an isotropic phase above 60 ${ }^{\circ} \mathrm{C}$ and a nematic phase below $54^{\circ} \mathrm{C}$. Thus, a coexistence of nematic and isotropic phase can be expected in an intermediate region as shown in the phase diagram. Such a narrow coexistence region has been known in liquid crystal/liquid crystal or liquid crystal/diluent systems,, 7 The same principle may be extended to a liquid crystal/polymer mixture. ${ }^{7}$ As demonstrated in a previous paper, 5 the depression of the $\mathrm{N}-\mathrm{I}$ transition temperatures with increasing polymer content could be observed by differential scattering calorimetry, depolarized light scattering and polarized optical microscopy. Below the N-I transition temperatures, the PMMA/E7 phase separates into polymer-rich and nematic LC domains.

To mimic liquid-liquid phase separation and nematic formation, a thermal quench experiment was undertaken at the $40 \%$ E7 composition by rapidly transferring the specimen from a single phase $\left(95^{\circ} \mathrm{C}\right)$ to room temperature. Figure 2 shows the development of multiple droplets under optical microscopic investigation. Then the droplets coalesce and form some interconnectivity. The initial droplets cannot be discemed under cross-polars, suggesting the lack of orientation fluctuations. These droplets occur due to liquid-liquid phase separation, although it is difficult to distinguish the mechanisms of phase decomposition from these micrographs. After several minutes, the domains become

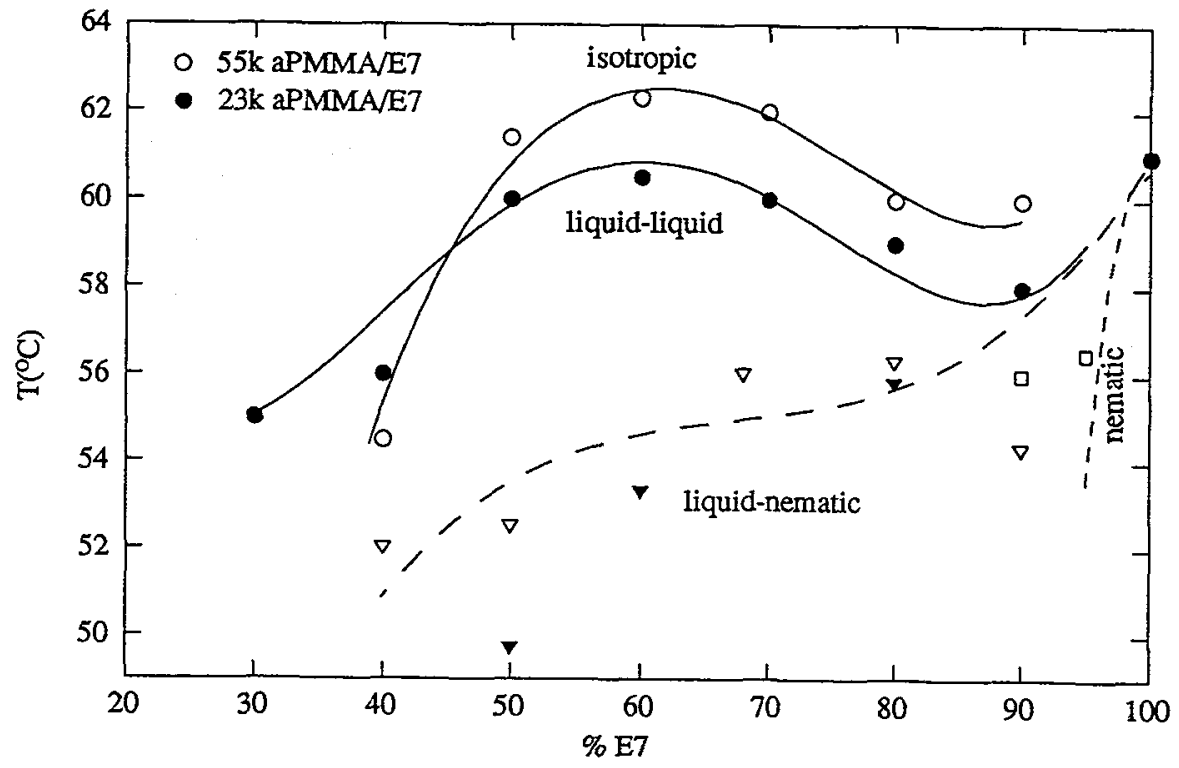

Figure 1. Cloud point temperature vs. composition phase diagram of aPMMA/E7 mixture. $\nabla$ and $\nabla$ represent depolarized light scattering and DSC of 23k aPMMA/E7. $\square$ is from polarized microscopy of 23k aPMMA/E7. 
birefringent as the concentration of liquid crystal molecules increases within the phase separated domains. When the local concentration of liquid crystal molecules exceeds the critical concentration, a typical Schlieren texture can be discemed within the growing domains. These domains not only grow in size, but also merge together to form a larger but non-uniform domain. Concurrently, the nematic disclinations are either annihilated or form a new disclination. The growth continues for several ten hours until all LC molecules are consumed or sucked into the growing LC domains, thus the matrix becomes dark.

To quantitative follow the dynamics of phase separation, $T$ quench experiments were performed under the light scattering set-up. Figure 3 shows a typical time evolution of scattering profiles of a T quench to $35^{\circ} \mathrm{C}$. A scattering peak, corresponding to the average periodic distance of the domains, was observed. The peak subsequently shifts to a lower angle as time elapses. There is a cross-over of scattering curves at large scattering angles, suggesting that larger domains grow at the expense of the smaller ones. These features resemble some characteristics of spinodal decompostion (SD), although it is by no means a proof without the early stage linear regime. It is rare to observe a scattering peak from droplets formed by nucleation and growth (NG) which is generally a heterogeneous process. Cumming et al. ${ }^{8}$ observed the NG in a low molecular weight polymer blend, that gave rise to higher order peaks if the droplets were monodisperse and uniformly distributed. The authors stressed that a mere increase of polydispersity factor of droplets by $7 \%$ could wash out the scattering maxima. It should be pointed out that the domains in the present study are nearly uniform in size and distributed evenly for some initial periods. Later, the coalescence of domains has led to a non-uniform size and shape. By that time, the domain structure is too large to be observed by light scattering.

The growth of domains was analyzed according to a power law, $q_{m} \propto t^{-\alpha}$, and by plotting the wavenumber maximum $\left(q_{m}\right)$, defined as $q_{m}=4 \pi / \lambda \sin \theta_{m} / 2$, against elapsed time in double logarithmic form for three T quenches (Figure 4). The kinetic exponent appears to change from -0.33 to -0.6 at 25 and $35^{\circ} \mathrm{C}$ quenches. The time scale covered by the initial slope corresponds to the growth of droplets where anisotropy was absent. In this stage, liquid-liquid phase separation may be dominant. The observed value corresponds to the exponent of $1 / 3$ which has been predicted by the classical evorporation - condensation mechanism. 9 The second slope of 0.6 corresponds to a late stage where nematic disclinations develop within the growing domains. Subsequently, pair annihilation takes place while the domains continue to coalesce. The $\mathrm{T}$ quench at $45^{\circ} \mathrm{C}$ yields a larger slope of 0.7 which is smaller than the exponent of 1 predicted by Siggia for the hydrodynamic flow region,? This value is somewhat larger than the exponent of $1 / 2$ reported by Cumming et al. ${ }^{9}$ for the NG of the blend of low molecular weight polyolefins. It may be speculated that the difference in diffusivity of coiled polymer and rigid LC molecules could affect the phase separation dynamics. At present, the interplay of liquid-liquid phase separation of a polymer/liquid crystal mixture and the nematic annihilation is still unclear.

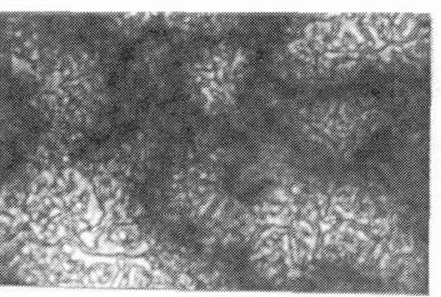

$5.5 \mathrm{~min}$.

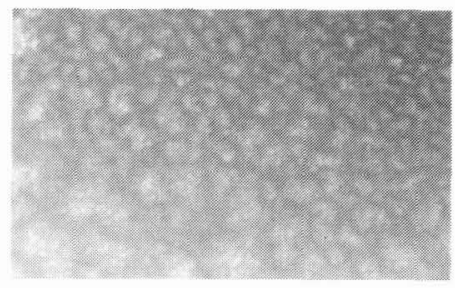

147

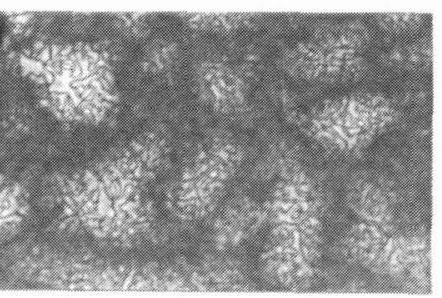

25.5

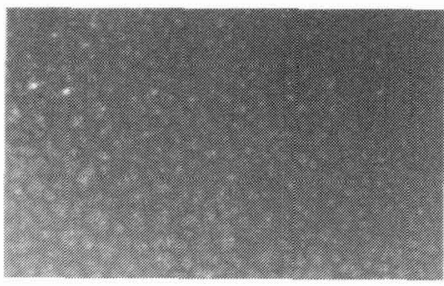

336

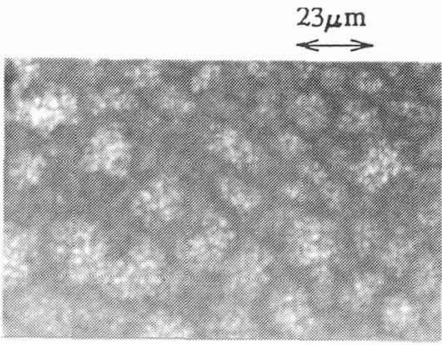

60

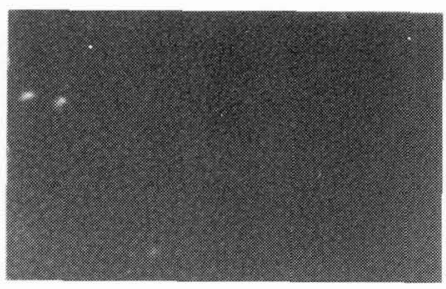

618

Figure 2. Structure evolution of the $60 / 40$ aPMMA55/E7 following a temperature quench from $95^{\circ} \mathrm{C}$ to $35^{\circ} \mathrm{C}$ observed under polarized optical microscopy. 
Acknowledgement: Support of this work by the National Science Foundation - Science and Technology Center for "Advanced Liquid Crystal Optical Materials: ALCOM" \# DMR89-20147 is gratefully acknowledged.

\section{References}

1. J.W. Doanne, N.A. Vaz, B.G. Wu and S. Zumer, Appl. Phys. Lett., 48, 269 (1986).

2. N.A. Vaz, G.W. Smith and G.P. Montgomery, Jr., Mol. Cryst. Liq. Cryst. 146, 17 (1987),

3. T. Kajiyama, A. Miyamoto, H. Kikuchi and Y. Morimura, Chem. Lett., 1989, 813 (1989).

4. Y. Hirai, S. Niiyama, H. Kumai and T. Gunjima, SPIE 1257, 2 (1990).

5. T. Kyu, M. Mustafa, J.C. Yang, J.Y. Kim and P. Palffy, in "Polymer Solutions, Blends, and interfaces," I. Noda and R.N. Rubingh Eds. Elsevier, p245 (1992).

6. P. Palffy-Muhoray, J.J. de Bryun and D.A. Dunmur, Mol. Cryst. Liq. Cryst1., 127, 301 (1985).

7. V.K. Kelkar and C. Manohar, Mol. Cryst. Liquid Cryst., 133, 267 (1986).

8. A. Cumming, P. Wiltzius and F.S. Bates, Phys. Rev. Lett, 65, 683 (1990).

9. J.D. Gunton, M. San Miguel and P.S. Sahni in "Phase Transitions and Critical Phenomenon," C. Domb and J. Lebowitz, Eds. Academic, New York, vol 8, 1983.

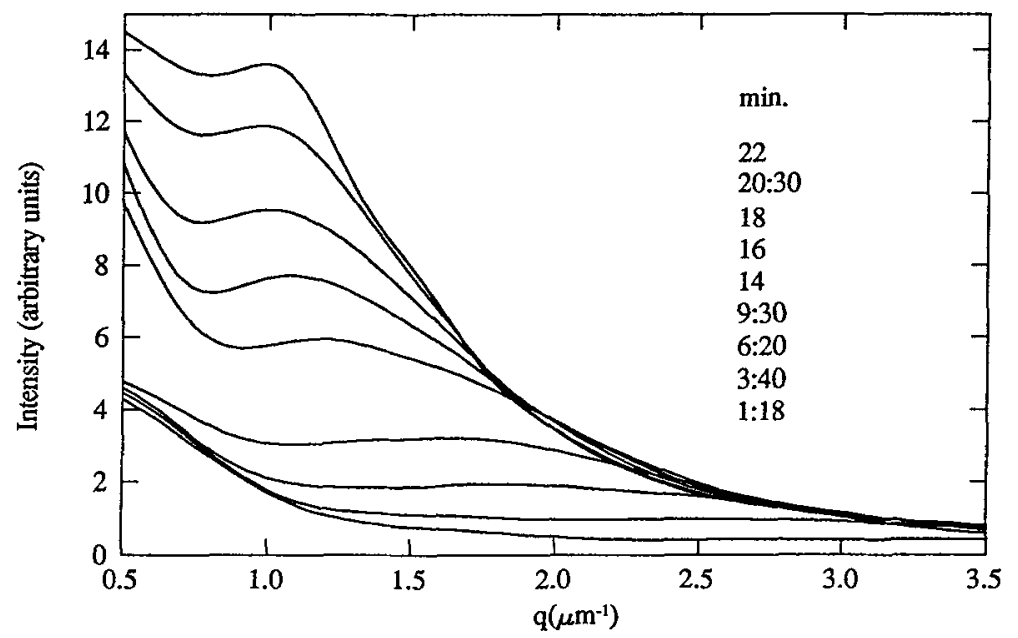

Figure 3. Time evolution of scattering peaks of aPMMA55/E7 (60/40) PDLC film quenched from $95^{\circ} \mathrm{C}$ to $35^{\circ} \mathrm{C}$.

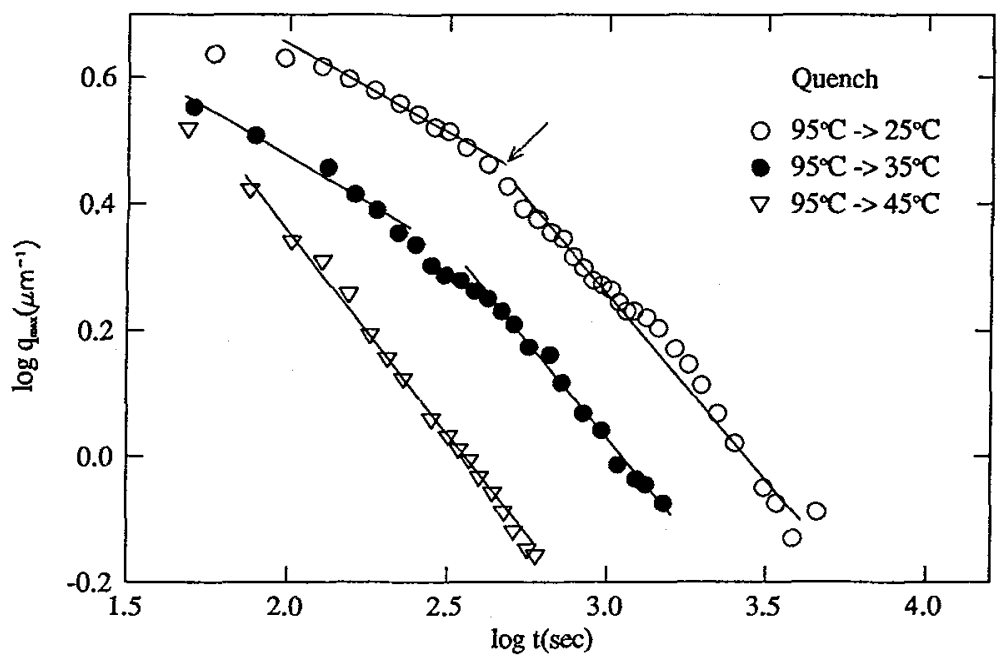

Figure 4. Logarithmic representation of $q_{\text {ox }}$ vs. time for aPMMA55//E7 (60/40) for three different temperature quenches. 